\title{
Comunidades da nova era no Planalto Central \\ utopia, ideologia e reafirmação da ordem
}

\author{
AICO SIPRIANO NOGUEIRA \\ "She's on the horizon... I go two steps, she \\ moves two steps away. I walk ten steps and \\ the horizon runs ten steps ahead. No matter \\ how much I walk, I'll never reach her. What \\ good is utopia? That's what: it's good for \\ walking" (Galeano, 1995)*
}

RESUMO: Este artigo analisa a constituição de uma comunidade alternativa no planalto central do Brasil, a partir do que se convencionou chamar de "novas formas contemporâneas de sociabilidade". Através de uma discussão teórico-conceitual sobre comunidade, comunidade utópica, mito, ideologia, utopia e imaginário, o texto sugere a possibilidade de se pensar a idéia de alternativa ao sistema social vigente enquanto expressão, ao mesmo tempo, do pensamento conservador e da possibilidade de construção do novo.

lguns dos principais compêndios de sociologia definem o conceito de ressocialização como "o reaprendizado de normas e sanções culturais e o retorno ao sistema social por aqueles que, voluntária ou involuntariamente, deixaram tal sistema (como prisioneiros reentrando na sociedade ou expatriados retornando do exterior), de modo que eles possam ser plenamente aceitos dentro do contexto social outrora negado"(Marshall, 1994).

Esse tema tem estado presente em vários estudos sociológicos clássicos, assim como a ligação entre o rompimento identitário dos sujeitos, em face de uma sociedade negada, e a criação imaginária de uma sociedade ideal, tendo como base dessa elaboração o mito da comunidade

PALAVRAS-CHAVE: utopia, comunidade, imaginário, ideologia, mito, contracultura.

Doutorando do Departamento de Sociologia da FFLCH - USP 
O presente artigo constitui parte da reflexão contida na Dissertação de Mestrado em Sociologia apresentada ao Departamento de Sociologia da FFLCHUSP (Nogueira, 1986).

*"Ela está no horizonte...Me aproximo dois passos, ela se afasta dois passos. Caminho dez passos e o horizonte corre dez passos. Por mais que eu caminhe, jamais a alcançarei. Para que serve a utopia? Para isso: serve para caminhar." utópica. Não obstante tais estudos, muito pouca atenção tem sido dada aos mecanismos de ressocialização contidos nas chamadas "novas formas contemporâneas de sociabilidade".

Este artigo busca, justamente, centrar atenção sobre a tentativa de construção de uma dessas "novas formas" de expressão social, uma comunidade alternativa no Planalto Central do Brasil, procurando elucidar como o chamado mito da comunidade utópica expressa-se atualmente. Busca também compreender como a idéia de tópos e a questão da temporalidade se articulam no imaginário, de forma a transfigurar em instrumentos de legitimação dessa mesma ordem negada mecanismos apresentados e vividos subjetivamente como meios de vida em comum e de resistência ao sistema social combatido.

A maneira pela qual esse processo ocorre, e que não se desvenda de forma explícita para os personagens nele envolvidos, talvez possa ser melhor elucidada a partir de uma leitura sociológica na qual os diversos elementos presentes nessas experiências sejam analisados. Questões como a do imaginário, enquanto atualização mítica; da comunidade, enquanto veículo pela qual essa atualização se dá; e do simbólico, enquanto suporte por meio do qual a ideologia se transmuta na utopia, forjando a idéia do novo; talvez possam nos fornecer pistas para compreendermos o processo pelo qual o conservantismo muitas vezes se metamorfoseia em "cultura alternativa", agindo como elemento de recondução desses atores sociais à sociedade de origem.

Assim, cremos que a idéia de negação e de construção de novos laços societários, a partir de um estudo de caso, pode tomar novos contornos e abrir uma possibilidade de análise bastante profícua. E esse conjunto de imagens sobre a sociedade ideal, enquanto alternativa concreta ao sistema social vigente, lido com uma "lente sociológica", pode nos revelar, talvez, algo mais que a simples aspiração por "viver diferentemente". Pode nos mostrar como operam, às vezes de maneira quase subliminar, mecanismos sutis de reeenquadramento e controle sociais, assim como nos inspirar a pensar sobre a possibilidade do "novo" enquanto construção da utopia.

Nos últimos vinte anos, a região que compreende o Planalto Central do Brasil tem recebido um afluxo muito grande de pessoas, vindas das principais regiões do Brasil e de várias partes do mundo. Esses indivíduos para lá se deslocam buscando uma alternativa de vida àquela vivida nos grandes centros urbanos e inspirados por um imaginário de predestinação daquela região como o berço da chamada "nova era".

Diferentemente dos inúmeros migrantes que afluem para aquela parte do país onde se localiza a capital, Brasília, fugindo das agruras da seca do nordeste ou tentando uma opção de emprego já cada vez mais rara nos tradicionais grandes centros, verifica-se que um grupo diferenciado de pessoas se destaca da multidão de retirantes. São pessoas geralmente pertencentes às classes médias urbanas, compostas sobretudo por profissionais liberais e por outros tipos de profissionais qualificados. Quase 
sempre tiveram uma vida sem privações materiais, freqüentaram boas escolas, gozam de bom nível cultural e estavam bem posicionados profissionalmente em suas respectivas cidades.

No entanto, seguindo uma lógica oposta àquela verificada entre a maioria dos migrantes brasileiros, essas pessoas têm se deslocado paulatinamente às cidades do Planalto Central e procurado não uma maneira de sobreviver às asperezas da vida, mas um jeito de viver mais ligado à natureza e à espiritualidade, e criticando veementemente o crescente consumismo verificado no mundo contemporâneo.

Dentre as diversas formas de manifestação desse tipo lá verificados, como grupos religiosos (sobretudo religiões orientais), outros praticando medicina alternativa, alimentação natural, bioenergética, etc., uma se destaca das demais por uma opção de vida alternativa mais radical. São as chamadas "comunidades alternativas rurais", que proliferaram pelo país, sobretudo na década de 70, e que ainda hoje são um forte componente do que se convencionou chamar "movimento alternativo" no Planalto Central brasileiro.

Fortemente influenciadas pelo movimento de contracultura iniciado nos anos 60, as "comunidades alternativas" buscam, através da vida comunitária, uma maneira de vivenciarem um modo viável de resistência aos efeitos negativos da vida moderna, marcados, sobretudo, por um crescente individualismo e por um distanciamento cada vez maior das pessoas com o ambiente natural.

Embora o surgimento de tais "comunidades", em diversas partes do Brasil, constituam manifestações singulares, elas surgem como fruto de um mesmo momento histórico e processos sociais específicos, o que permite sua leitura sociológica enquanto mesmo fenômeno social. Para além de uma análise como caso particular e isolado, a constituição de tais "comunidades" parece inserir-se numa tendência mais geral, verificada nas sociedades ocidentais, dos homens imaginarem estruturas sociais que venham substituir as atuais e indesejadas.

Dentre as muitas experiências dessa natureza que se desenvolveram e se desenvolvem no Brasil, uma em particular chama a atenção pelo caráter de durabilidade enquanto experiência comunitária. Isso porque, ao contrário de quase todas as "comunidades" observadas, que sobrevivem, no máximo, por um prazo que varia de um a dois anos, em Pirenópolis, cidade que compõe a região citada, tem se desenvolvido uma experiência desse tipo por cerca de 15 anos, o que nos oferece uma possibilidade de análise mais detida de tal fenômeno.

Apesar da longa vida, a "Comunidade FraterUnidade", ou simplesmente Fráter, como é conhecida, apresenta uma característica em comum com os demais agrupamentos observados e também ligada à questão do tempo. Isso porque, embora as outras experiências tenham um prazo de vida muito curto, a Fráter, ainda que exista há cerca de 15 anos, apresenta uma rotatividade muito grande de seus componentes, sendo que a renovação constante de seus 
1 “(...) Através da história do espírito, o desejo utópico gerador de imagens, embora esteja, como tudo o que cria imagens, enraizado nas profundezas, nada tem a ver com o instinto ou com a auto-satisfação. Ele se acha ligado a algo superpessoal que se comunica com a alma, mas que não se acha condicionado por ela. $\mathrm{O}$ que aqui predomina é o anseio pelo que é justo, anseio que se experimenta na visão religiosa ou filosófica como revelação ou idéia e que, por sua essência, não pode se realizar no indivíduo mas somente na comunidade humana. A visão daquilo que deve ser, muito embo- componentes e a incapacidade dos mesmos em permanecer por um tempo maior constitui o primeiro aspecto a chamar a atenção na comunidade. Entre todas as 5 visitas realizadas, num prazo de 3 anos, os únicos membros sempre verificados eram os da família do líder e então detentor legal da terra. Os demais haviam permanecido sempre por um prazo máximo que variava de um a um ano e meio, depois do qual, invariavelmente, voltavam para suas sociedades de origem retomando a vida outrora negada. Assim, o caráter efêmero das experiências "alternativas", ou dos seus membros no interior dessas, serviu como porta de entrada para compreensão do fenômeno em questão enquanto passagem, para, num segundo momento, procurar lançar luz sobre o processo de elaboração de novas representações sociais, bem como sobre o papel desse tipo de experiência enquanto agente ressocializador.

Para tanto, faz-se mister, inicialmente, uma pequena discussão acerca de dois conceitos-chave no entendimento do tema proposto: "comunidade utópica" e "comunidade". Num segundo momento, este texto busca centrar atenção sobre a comunidade objeto deste trabalho, procurando identificar dois aspectos que contribuem para que haja um rompimento identitário de tais sujeitos com a sociedade de origem, quais sejam, a maneira com que vivem a articulação espaço/tempo (enquanto estações climáticas) e a forma com que a comunidade aparece enquanto parte de um "processo de busca", no qual a questão espiritual desempenha um papel fundamental. Num terceiro momento, procurar-se-á analisar o tema proposto à luz dos conceitos de ideologia e utopia, a partir dos quais o tema da ressocialização emerge, permitindo que pensemos a possibilidade do "novo" enquanto reinvenção da utopia.

\section{A "sociedade" alternativa enquanto mito}

Podemos constatar, nos mais diferentes momentos históricos, a existência e reelaboração constantes de imagens sobre a construção de um ideal de sociedade que surge nas mentes dos homens, na maioria das vezes como resposta a uma realidade social negada e a algo que se verifica ao seu redor.

As reflexões sobre este tema podem ser encontradas numa gama de matrizes teóricas muito vasta. Vão desde humanistas como Martim Buber ${ }^{1}$, que atribuem a construção desse quadro de representações ao desenvolvimento de uma essência humana, que se efetiva apenas no campo social e como produto de uma visão crítica de uma realidade negada, até uma visão marxista, que afirma a existência dessa "essência" somente enquanto um produto de relações sociais ${ }^{2}$. Essas análises passam também por visões interacionistas, que buscam ver essas representações como um produto combinado de uma subjetividade nata com uma dimensão construída socialmente.

De qualquer forma, um dado marcante está no fato de que, em todas as épocas observadas, as representações desiderativas em torno de uma sociedade ideal aparecem sempre revestidas de um caráter paradigmático, tendo como um dos núcleos centrais de sua constituição 
um devir, pautado pelo modelo social a ser seguido. Há de se notar que, embora esse devir perpasse a história das sociedades ocidentais e esteja sempre ancorado num modelo societário - o que lhe confere, neste sentido, um caráter atemporal - tais modelos apenas são imaginados e se constituem a partir de um fluxo histórico determinado, sendo que é apenas nesse que encontram sua fonte inspiradora. Dessa forma, ao tomarmos as representações coletivas acerca da construção de uma sociedade alternativa: 1) como elaborações imaginárias em torno de um paradigma; 2) que carrega em si uma mensagem que transborda de significado, fornecendo aos homens um ideal de vida societária; 3) que se destaca das demais representações por seu caráter atemporal e que, ao mesmo tempo que transcende a realidade vivida só encontra sentido agindo nessa mesma realidade, estamos nos situando, pois, em pleno conceito de "mito".

É importante também notar que as construções míticas e sua relação com a realidade vivida constituem tema não apenas das sociedades ditas "primitivas", mas também da sociedade moderna. Nas primeiras, a existência de um arquétipo, de um modelo celestial para o qual o homem remete constantemente o seu viver - através dos processos rituais - "sacraliza" o presente, fazendo com que a vida real seja "transportada" para um tempo mítico, dos heróis criadores da sociabilidade, tornando o mito da criação parte integrante e constante da vida. Nesses termos, constitui sempre um tempo cíclico, de completude e de recriação constantes. Assim, a realidade vivida fornece os elementos através dos quais os modelos míticos ganham força e substância de "verdade", pois - como nos casos dos mitos cosmogônicos - a própria existência do mundo presente o prova e a vida real dos homens age no sentido de ancorar e consubstanciar a eficácia dessa criação (cf. Eliade, 1992).

Da mesma forma, o homem moderno também constrói seus mitos e tanto o homem "primitivo" quanto o moderno ritualizam suas ações cotidianas como forma de vivenciá-las e conferir-lhes substância de verdade. A diferença é que o homem moderno nem sempre remete sua existência a tempos primordiais, mas promove, muitas vezes, a possibilidade de superação, de rompimento do caráter cíclico que marca o tempo das "sociedades arcaicas", através do desenvolvimento de uma "consciência histórica" (cf. Heller, 1982, p. 9).

As construções míticas na sociedade moderna nos falam de um novo tempo, e o momento em que esses projetos devem se concretizar também reflete as tendências do imaginário ao longo da história ocidental. Seja através de uma volta à comunidade, através de uma idealização e busca das "formas mais puras" de relacionamento do homem com a natureza, que marcaram o chamado pensamento conservador; seja com um olhar voltado para o presente, numa perspectiva liberal ou mesmo num futuro a ser construído a partir da crítica incessante às formas já vividas até então, que caracteriza o chamado pensamento radical. ra às vezes pareça independente da vontade pessoal, não pode ser separada da atitude crítica em face da atual maneira de ser do mundo humano. $\mathrm{O}$ sofrimento que nos causa um sistema absurdo prepara a alma para a visão e o que esta vê reforça e aprofunda a compreensão da inexatidão do erro" (Buber, s/d, p. 18).

${ }^{2} \mathrm{Na}$ VI tese sobre Feuerbach, Marx afirma: "Feuerbach dissolve a essência religiosa na essência humana. Mas a essência humana não é uma abstração inerente ao indivíduo singular. Em sua realidade, é o conjunto das relações sociais" (Marx \& Engels, 1987, p. 13). 
No caso dos projetos de uma sociedade alternativa, cremos que o principal mito que sustenta a construção desse imaginário é precisamente o mito da comunidade utópica, que traz como modelo, entre outras coisas, uma vida integrada à natureza e a busca de uma "pureza interior". Esse imaginário, ao mesmo tempo que se aproxima e que é construído a partir desse mito, se afasta dele quando quebra seu círculo de existência, historicizando-se. Portanto, embora a base de sustentação do imaginário em torno de uma sociedade alternativa resida sempre num modelo social, o momento histórico fornece sempre os elementos para sua ultrapassagem enquanto mito, diante da necessidade de objetivação do querer humano.

Em essência, podemos afirmar que os mitos, particularmente aqueles que apontam para um ideal de sociedade, expressam um "rearranjo de elementos históricos" que, ao se combinarem de forma particular, traduzem uma elaboração coerente e ordenada da vida social (cf. Arruda, 1990, p. 129). Nesses termos, sua compreensão e possível desvendamento exigem sempre uma imersão nos processos sociais específicos que lhe fornecem suas matrizes significativas, assim como, da mesma forma, a detecção dos "sujeitos sociais" que protagonizam tais elaborações em momentos históricos determinados (cf. Arruda, 1990, p. 129).

No entanto, embora a história tenha possibilitado que o homem moderno rompesse o caráter cíclico que marca o tempo nas "sociedades arcaicas", muitas vezes uma visão conservadora impera na criação dos mitos de uma sociedade alternativa, operando no sentido do restabelecimento de laços antigos; procura-se uma volta às origens, às raízes de uma sociabilidade perdida no tempo ou mesmo uma forma de relação mais direta e "pura" do homem com a natureza. Procura-se, em suma, o restabelecimento de uma expressão social marcada pela forma comunidade.

\section{O querer objetivo transfigurado em natureza: a noção de comunidade}

A maneira pela qual o processo de elaboração mítica se dá encontra na forma comunidade um modo de expressão que está presente nos projetos que direcionam os movimentos sociais, principalmente os de cunho conservador.

Dentro das diferentes acepções em que o termo comunidade é conceituado no âmbito da sociologia - sociologia americana e a noção de sociedade local; sociologia européia e a noção de comunidade de sangue e espírito (cf. Nisbet, 1969, cap.4) -, é necessário destacar que a idéia de comunidade surge quando esta, enquanto forma básica de expressão social, deixa de constituir o fundamento da vida dos homens. Ou seja, a idéia de comunidade aparece quando a matriz de existência social passa a se constituir na sociedade e o entendimento das significações que a norteiam só pode ser conseguido a partir do confronto entre as noções de comunidade e sociedade.

Podemos encontrar em Tönnies uma importante distinção entre ambas, tendo como elemento básico dessa diferenciação o tipo de "querer" 
embutido em cada uma delas (cf. Tönnies, 1947, p. 119). Na sua visão, a sociedade é produto da reflexão e do cálculo, onde um querer subjetivo se consubstancia, e o crescimento da sociedade se dá através da racionalização do mundo e do querer objetivamente constituído.

Por oposição, a comunidade surge como uma noção que procura dar conta das esferas não racionalizadas da vida, onde os homens viveriam em "estado puro" e unidos, "apesar de todas as separações" (cf. Tönnies, 1947, p. 65). Assim, a comunidade se revela como uma forma "natural" da vida social e essa noção é concebida apoiando-se na suposição de que ela existe, na realidade, como um remanescente pré-capitalista vivendo nos interstícios do próprio capitalismo.

A discussão que Mannheim opera sobre este conceito, dentro da teoria social, permite que avancemos nesta discussão. Em sua visão o conceito de comunidade se insere no que chamou de "consciência do tradicionalismo" e, portanto, como expressão do pensamento conservador. Mannheim analisa a constituição desse pensamento como dizendo respeito a um modo de vida irracional, mas que expressa um estilo de pensamento referido a um modo de vida capitalista de se pensar. Conclui que o conservadorismo acaba se valendo do racionalismo para exprimir-se, sendo que a constituição do pensamento conservador combina, paradoxalmente, idéias e concepções pré-capitalistas com o racionalismo, combinação essa que se encontra na base da constituição da sociologia, sobretudo em autores como Durkheim e Le Play (cf. Nisbet, 1969, cap. 4).

Assim, é o pensamento racional, base do querer objetivado em sociedade, que funda a idéia de comunidade (tanto em termos científicos como do senso comum) e o que encontramos na periferia da sociedade não é mais a comunidade, mas sim a sociedade objetivada e transfigurada. Nesses termos, a idéia de comunidade exprime não uma realidade periférica e autônoma da vida, mas sim uma dimensão estritamente relacionada com a sociedade. "É enquanto utopia que a comunidade estipula uma maneira de conhecimento da realidade e de contraposição ao presente. A utopia comunitária constitui uma perspectiva de avaliação da sociedade e das relações do grupo que a vivencia com a sociedade" (Martins, 1973, p. 36).

É dentro dessa discussão e dentro dessa visão de comunidade apontada por Martins que emerge o objeto deste trabalho e que orienta os passos da análise aqui desenvolvida. Uma comunidade alternativa que surge: 1) em contraposição e como opção a uma idéia de sociedade, por suposto negada; 2) que se constrói a partir e em torno do mito da "comunidade utópica", cujo quadro de representações que orienta a idéia de "vida alternativa" se nutre, justamente, da negação da realidade social vivenciada nos locais de origem dos sujeitos participantes de tal projeto.

Há de se notar que, embora este trabalho veja a forma comunidade como uma maneira particular de expressão e de compreensão da própria sociedade, o termo aqui é assumido quando referindo ao objeto de estudo, pois assim seus integrantes se vêem e se identificam. 


\section{O universo da comunidade}

A FraterUnidade (sic) é uma comunidade que se localiza na zona rural da cidade de Pirenópolis, Estado de Goiás, Brasil, num vale cortado pelo principal rio que abastece a cidade, o Rio das Almas. Essa região foi batizada pelos alternativos de "Vale Dourado" e nasceu de uma experiência alternativa anterior, chamada Comunicampo, sediada no Estado de Mato Grosso, que teve início em fevereiro de 1975 e durou cerca de nove anos. Por lá passaram nesse período, segundo informações de antigos integrantes, cerca de 600 pessoas, a maioria delas originárias do movimento hippie.

Após nove anos de convivência, quando buscavam a auto-suficiência econômica através de diversos trabalhos, principalmente aqueles ligados à terra, seus componentes tiveram de se mudar devido à instalação de uma fábrica de cimento ao lado da comunidade. Nessa época, um grupo de apenas 3 pessoas resolveu sair e comprar uma outra terra, reiniciando um novo projeto de vida. Após procurarem por diversas regiões do país, em fevereiro de 1984 compraram 15 alqueires no município de Pirenópolis, onde recomeçaram. Em abril do mesmo ano já tinham um estatuto e a comunidade registrada juridicamente como entidade civil. Desde então, muita coisa mudou na Fráter. Novos membros aderiram à experiência e hoje a comunidade sobrevive em parte com o que produz através do plantio, mas o maior rendimento vem principalmente através de doações.

Consideram-se alternativos por diversos motivos, a começar por sua organização cotidiana, sua divisão de tarefas e horários, pela proposta de educação que tentam implementar, pela alimentação e pela ênfase que dão à espiritualidade. Possuem uma escola, um templo, 6 casas para famílias, uma casa para estagiários, uma casa para visitantes, uma cozinha comunitária e uma biblioteca. Uma infra-estrutura invejável, diante dos padrões das demais comunidades existentes no Brasil ${ }^{3}$.

Do ponto de vista da organização política interna, oficialmente não existe uma liderança. Há um revezamento periódico nas principais funções administrativas, mas é muito clara e decisiva a influência dos mais antigos, principalmente a do detentor legal da posse da terra, que recentemente transformou parte da propriedade numa espécie de fundação.

No que diz respeito aos trabalhos realizados, esses baseiam-se em horta, limpeza, apicultura (numa escala muito reduzida), roça (também em pequena escala), compostagem e oficinas de artesanato. São sempre realizados no período da manhã e com uma duração de duas horas, quatro vezes por semana, sendo que o período da tarde é livre. Além desses traba-

${ }^{3}$ Para um estudo comparativo entre três comunidades alternativas brasileiras, sob a perspectiva da autogestão, cf. Abreu (1989). lhos, alguns membros procuravam algum tipo de atividade na qual pudessem aferir algum ganho, que era sempre uma atividade artesanal: confecção de peças de vestuário, tecelagem, etc... À exceção da horta e do pomar, responsáveis por uma pequena parcela do consumo de hortaliças, legumes e frutas da comunidade, produtos como grãos e cereais bem como material de 
limpeza e de manutenção eram comprados na cidade. Para isso, contam com o dinheiro de contribuições que são pedidas aos visitantes, assim como uma "caixinha" recolhida entre os residentes.

Dentro da análise aqui proposta, o principal aspecto a ser sublinhado é a flutuação de pessoas na comunidade e o seu retorno à sociedade de origem. Embora isso garanta uma constante presença de mão-de-obra, o fato das pessoas não se fixarem não permitia a continuidade dos trabalhos começados, na maioria das vezes, inviabilizando-os.

Devido a essa renovação constante da comunidade a cada ano, desenvolveu-se um senso de desprendimento muito grande daqueles poucos que ficam - por um período maior - em relação aos que passam, sendo que o contato com os que saíram se dá com pouca freqüência, inviabilizando a obtenção de informações mais precisas que nos permitissem saber com maior exatidão o verdadeiro paradeiro de todas as pessoas que por lá passam. É de domínio comum na comunidade que a grande maioria volta para os seus lares e que lá permanece, e que outros poucos continuam procurando novas experiências em outros agrupamentos.

O fato das "comunidades alternativas" constituírem um ponto de passagem para a "reintegração social", como já citado, é a primeira coisa que chama a atenção nesse tipo de experiência. No caso específico da Fráter, um olhar mais atento permite que percebamos que basicamente dois elementos presentes em tal agrupamento, como serão descritos abaixo, contribuem para que a reintegração social aconteça. O primeiro deles é a maneira pela qual tais sujeitos vivem a articulação "espaço/tempo" e a idéia de "processo", de maneira a fazê-los estarem sempre presos à realidade outrora negada, não permitindo que haja um rompimento identitário dessas pessoas com a sociedade mais ampla, reconduzindo-as à sociedade de origem.

\section{Chuva e seca: tempo, reflexão e vida comunitária}

De uma visita a outra, realizada em períodos diferentes do ano, um dos primeiros aspectos observados é que o ritmo da comunidade obedece o ciclo das estações climáticas. No centro-oeste do país, ao contrário de outras regiões brasileiras, têm-se marcada de forma muito nítida não quatro, mas duas estações. São elas, primeiramente, a estação da seca, compreendida pelos meses de março até início de outubro, e a estação das águas, cobrindo, aproximadamente, do mês de outubro até meados de março. Durante cada uma delas, a natureza se impõe de tal forma na vida das pessoas da região que o tempo acaba por ser vivido e pensado a partir dessa relação dicotômica. Espera-se pela chuva e espera-se pela seca, sabendo que ambas sempre chegam, cada uma em sua época, trazendo consigo um modo específico de sociabilidade e de relação do homem com o ambiente natural. Nestes termos, enquanto a estiagem permite relações sociais mais voltadas para a exterioridade da vida dos pequenos grupos e uma atividade econômica com um contato 
${ }^{4}$ Em se tratando especificamente das "comunidades alternativas", estudiosos desse tipo de experiência, como Benjamin Zablocki, têm preferido chamá-las "comunidades intencionais" (intentional community). O autor cita, para isso, uma definição formulada por uma federação de comunidades nos Estados Unidos: "Uma comunidade intencional é um grupo de pessoas associadas (voluntariamente) com o propósito de estabelecer todo um modo de vida. Dessa maneira, ela exibirá, em algum grau, cada uma das seguintes características: localização geográfica comum; interdependência econômica; desenvolvimento e troca interna de elevação espiritual, social, cultural e educacional. Um mínimo mais direto com a natureza, as águas, ao contrário, impelem as pessoas a uma sociabilidade mais voltada à esfera da intimidade e limita o trabalho às atividades de manutenção do que havia sido feito na estação passada.

Sempre que era manifestada a nossa intenção de se fazer uma visita à comunidade, a primeira coisa que nos era mencionada era a conveniência ou não de fazê-la na época proposta, diante do clima apresentado. Se a época era de seca, a visita era sempre incentivada, procurando-se ressaltar a intensa atividade vivida pelo grupo nessa época. Ao contrário, se a estação era de chuva, havia sempre a tentativa de dissuasão diante da idéia cogitada, sob a alegação de que, nessa época, a comunidade ficava "morta, sem vida, vazia" e que valeria a pena esperar pela estiagem. Existe uma expressão corrente entre os alternativos, que diz que " ficar em Pirenópolis na época das chuvas, só mesmo se for para pegar mofo", numa alusão a um período que chove de forma torrencial, quase que ininterruptamente.

Apesar dos conselhos, foram realizadas duas visitas durante a época das chuvas e duas durante a seca, podendo ser constatada, de fato, uma diferença muito grande, tanto no ritmo das atividades como no número de pessoas presentes. Durante a seca, quando incitados a falar sobre o seu presente ou o seu futuro na comunidade, não se pensava em termos de meses ou anos, mas em termos de água ou não água, como se os 12 meses fossem reduzidos a apenas dois: março e outubro, ambos marcando o início e o fim de um ciclo. Evidentemente, a comunidade, estando inserida nesse contexto, compartilha desse ritmo imposto pela natureza, com a especificidade de, tendo sido constituída não de uma maneira "natural" mas a partir da intencionalidade 4 de seus membros, esses viverem tal ritmo reinventado a partir dessa situação particular.

Quando pensamos na maneira como esse ciclo natural - chuva e seca - se impõe sobre o modo de vida dos habitantes da região estudada, estabelecendo em cada uma dessas fases uma forma específica de sociabilidade, percebemos, no que se refere aos alternativos, que os ciclos naturais impõem algo mais que formas de relações sociais. Podemos constatar que a chuva e a seca determinam também uma maneira dos alternativos estabelecerem uma conexão com o seu passado e o seu futuro na sociedade de origem, e essa especificidade em relação ao habitante nativo da cidade só pode ser compreendida a partir da situação particular que o objeto desse trabalho vivencia em Pirenópolis, como pessoas que vieram de outras localidades.

Enquanto os nativos vêem a sua dimensão espacial circunscrita ao município de Pirenópolis e dentro dessa área concebem e vivem a articulação espaço/tempo, os alternativos, ao contrário, sendo todos eles forasteiros, vindos das mais diversas regiões do Brasil, concebem a dimensão espacial na qual se movimentam em dois âmbitos. O primeiro deles diz respeito ao espaço ocupado e vivido dentro da própria comunidade, e cuja disposição permite que o imaginário alternativo seja vivido num período específico do ano. A segunda dimensão na qual o espaço se divide extrapola em muito tanto o lócus da comunidade como do município de Pirenópolis, indo completar-se, na grande maioria das 
vezes, na sociedade de origem. Diante da "impossibilidade" de conviverem com as chuvas, sob o risco de se ficar "mofado", impõe-se a necessidade de evasão que, invariavelmente, se completa nos seus antigos lares.

Dessa forma, diante dessa visão de um tempo clivado em época de trabalhar e época de se ausentar, criou-se na Fráter a idéia de que "tudo tem que se redefinir a partir de outubro; em outubro tenho que decidir para onde vou", pois quase todos ali o fazem. A época da seca acaba constituindo um momento de reflexão acerca do futuro, e de um futuro muito próximo, que chega agora, em outubro.

Se o tempo (chuva e seca) entre os alternativos é sempre pensado dentro dessa dicotomia, a partir da qual o viver em comunidade aparece para esses sujeitos como impossibilidade, a articulação que estabelecem com a dimensão espacial - ou seja, o lugar geograficamente definido convertido em espaço pela presença do social - acaba por projetá-los para fora da comunidade e a referência que possuem é sempre a da sociedade de origem. Desse modo, os ciclos naturais agem de forma a proporcionar uma reflexão sobre a própria situação pessoal e social vivida por tais sujeitos, acabando por contribuir no sentido de reconduzi-los à sociedade de origem.

É devido a isso que a época das chuvas é uma “época morta, sem vida, vazia". É um período de renovação. Com ela, não apenas a natureza se renova, não apenas tudo nasce ou renasce com vigor, mas também os próprios homens ganham uma vida nova, e assim que as águas se vão, a comunidade se transforma quase que totalmente. Aos poucos chegam novos membros, animados com a possibilidade de viver diferentemente e se "reencontrarem" a partir de um contato mais direto com o ambiente natural. Após a chuva iniciase um novo ciclo, não apenas da própria natureza, mas também um novo ciclo de homens que se renova a cada ano. Não é à-toa que a cada visita realizada uma comunidade totalmente diferente era encontrada.

\section{As conexões com a sociedade de origem e idéia de vida comunitária enquanto processo}

Outro importante aspecto a ser ressaltado, e que contribui no sentido de fazer com que a comunidade acabe por ser vista enquanto um ponto de passagem, reside na maneira com que a espiritualidade ${ }^{5}$ é vivida entre seus membros. Este constitui um elemento crucial na tentativa de compreensão da ressocialização enquanto parte de um processo de busca, onde a Fráter aparece como uma etapa.

O próprio nome "Fraternidade Espiritualista FraterUnidade" já denota essa importância, pois indica uma união de irmãos feita a partir e em torno da questão espiritual. Através dessa, busca-se proporcionar a seus membros um auto-conhecimento pessoal, tendo como base "uma vida integrada à natureza" e o desenvolvimento da espiritualidade, sendo que esta é um dos principais pilares que sustentam a sua existência. de três famílias ou cinco membros adultos é requerido para constituir uma comunidade intencional" (Zablocki, 1980, p. 19). Cf. também o interessante estudo feito por Abrams e Macculloch (1976), baseado nas comunidades e no movimento comunitário britânico. Nesse trabalho, os autores procuram examinar o sucesso e fracasso de algumas experiências alternativas à luz de teorias sociológicas clássicas que visam explicar os fundamentos da coesão e da solidariedade social, assim como o relacionamento do indivíduo com a sociedade.

5 Sobre uma discussão mais detalhada acerca da questão espiritual na FraterUnidade, cf. Nogueira (1986). 
Assim, a base do sistema religioso na Fráter foi definida como sendo a ioga e a meditação, praticadas diariamente na comunidade em momentos preestabelecidos. Através desses momentos, busca-se uma união entre o corpo, a mente e o espírito, bem como uma harmonia desses com o universo.

Sobre esse tema, muito se tem falado acerca de uma contraposição marcante, verificada entre os sécs. XIX e XX, em que o primeiro é visto como o século no qual o racionalismo imperava, enquanto o séc. $X X$, sobretudo em sua segunda metade, tem sido freqüentemente conceituado como um momento em que os homens como que redescobriram uma dimensão sagrada em suas vidas. Alguns autores chegam mesmo a falar numa espécie de "reencantamento do mundo" (cf. Unger, 1991), e esse fenômeno aparece hoje revestido por uma dimensão não apenas religiosa, espiritual, mas também por uma redescoberta do homem em sua dimensão ecológica, ou seja, como parte integrante do mundo natural e, num plano mais amplo, do próprio cosmos.

Não é à-toa que muito do que se produz hoje em dia, em termos do que se convencionou chamar "literatura esotérica", trata justamente da chamada auto-descoberta, dentro da qual o reconhecimento das conexões que o homem estabelece com o mundo natural e com o universo é parte fundamental. Nessa literatura, a descoberta de si mesmo se dá, invariavelmente, através de caminhos sempre tortuosos, ao longo dos quais sinais vão sendo encontrados e cabe àquele que trilha esse caminho ser vigilante, observador de todos os detalhes, pois as minúcias podem esconder o sinal que indicará a próxima etapa a ser cumprida em direção à iluminação e a compreensão de si mesmo.

No entanto, é importante notar que esse é um processo constante, no qual se findam etapas menores que, quando juntas, constituem uma etapa maior que, por sua vez, pode encontrar seu término dando lugar a um novo estágio e assim sucessivamente. Cada grande etapa, quando cumprida, compõe um grau no caminho do auto-conhecimento, de maneira que esse nunca se completa totalmente.

No mundo alternativo, muito se fala nos grande mestres, nos grandes iluminados (Krishnamurti, Sri Aurobindo, Osho, São Francisco, etc.), e nos caminhos árduos que todos eles trilharam até que atingissem o grau de conhecimento que obtiveram. Embora sempre sejam vistos como uma espécie de "tipo ideal" na vereda do auto-conhecimento e para os quais todos olham almejando um dia atingir semelhante estágio, sabe-se também que se eles ainda estivessem vivos, estariam procurando se aperfeiçoar cada vez mais, pois estariam participando de um processo infinito que, segundo acreditam, não se completa na vida terrena.

É precisamente esse tipo de literatura que serve de suporte às práticas verificadas na comunidade. Apenas a título de ilustração, podemos citar um trabalho que se tornou um best seller não apenas entre o público em geral mas também entre os alternativos. Em $O$ diário de um Mago (1990), de Paulo Coelho, já no prefácio encontramos frases que darão a tônica desse livro e que, em certo sentido, também nos ajudam a compreender as trajetórias dos 
alternativos: "Todos os caminhos são mágicos se nos levam aos nossos sonhos"; "Quem corre atrás da magia quer um caminho para atingir seu sonho"; "A maravilha deste livro é que ele é uma promessa de que com seu pé e seu passo você é absolutamente capaz de fazer seu caminho, de atingir seu sonho e conquistar sua espada" (Coelho, 1990, p. 5). Essa obra nada mais é do que o relato de uma etapa do processo de auto-conhecimento e de aperfeiçoamento espiritual do autor - cujo símbolo, a seu término, é uma espada - através do chamado "Caminho de Santiago"6.

Ao longo do livro são relatadas as diversas etapas percorridas durante a viagem, nas quais o autor se depara, a todo o momento, com provações de toda espécie e deve estar sempre atento aos ensinamentos de seu mestre e aos sinais deixados ao longo do caminho. Ao final, após lutas com demônios, muito cansaço e muitos ensinamentos, completa-se mais uma trajetória: o autor consegue a sua espada, o símbolo de mais uma etapa cumprida e ascende mais um grau na hierarquia, tanto da confraria espiritual a qual pertencia, como na vereda do auto-conhecimento.

Podemos dizer que, entre os alternativos, a compreensão das trajetórias individuais, culminando na opção pela Fráter, passa, necessariamente, pela lógica do caminhante, do passante, e na qual a comunidade constitui mais uma etapa. E que todo esse processo de busca da compreensão de si mesmo e de seu lugar no universo aparece revestido de um amálgama de espiritualidade e ecologia, tão em voga na contemporaneidade. Quando perguntados acerca dos motivos que os levaram à comunidade e de como eram suas vidas na sociedade de origem, em todos os casos os entrevistados fizeram relatos de caminhos sempre tortuosos, que tiveram, invariavelmente, seu ponto de partida em crises pessoais decorrentes da falta de sentido que o mundo passou a ter para eles.

Essa busca encontra-se sempre associada à questão do tópos e o preenchimento do vazio interior deverá se dar num espaço onde as representações em torno de um ideal de sociedade ganhem substância de realidade, daí muitas vezes terem sido observadas múltiplas tentativas por parte desses agentes; daí o tortuoso caminho que a grande maioria deles afirma trilhar, com o objetivo da auto-descoberta e que, invariavelmente, faz com que retornem a seus antigos lares à procura de novos sinais que indiquem o próximo passo a ser dado.

\section{Utopia e ideologia: transcendência e reafirmação da ordem}

Quando se pensa no surgimento de uma comunidade alternativa, com pessoas chegando a todo momento, a imagem que surge é a de indivíduos difusamente espalhados por todas as partes, mas comungando de um sentimento em comum que é a necessidade de um reencontro com algo supostamente perdido dentro de cada um deles: o restabelecimento de laços indentitários com o meio em que vivem. Através de caminhos diversos, aca-
${ }^{6}$ Tal caminho constitui uma peregrinação a pé, percorrendo os setecentos quilômetros que separam a cidade francesa de San Juan Pied-de-Port da Catedral de Santiago de Compostela, na Espanha. 
bam por convergir e substancializar num tópos as respostas às suas indagações. Nestes termos, a comunidade alternativa surge como um produto desses sentimentos difusos e comuns e como possibilidade de um vivenciamento subjetivo concreto de uma vida alternativa.

Afora os efeitos subjetivos que se operam nesses agentes, no sentido de "prepará-los" para a volta à sociedade de origem, se deslocarmos o nosso foco de análise para uma perspectiva crítica desse modo de vida, procurando pensar o que representa a idéia da alternativa não diante de um efeito subjetivo, mas do sistema social como um todo, nossa discussão toma outros contornos em meio aos quais os conceitos de ideologia e utopia, da maneira como Mannheim os conceitua, podem nos auxiliar. Mais especificamente, cremos que, à luz desses conceitos, se torna profícuo analisar a idéia de comunidade em termos de uma aspiração de transcendência de uma realidade negada e de uma possível incongruência entre o que busca atingir e a realidade sobre a qual se funda.

Todavia, antes de passarmos a essa análise, é mister que sublinhemos uma vez mais a questão da transitoriedade dos membros, fato que, segundo informações, ocorre também em outras experiências "alternativas" e que, de tão evidente, acaba até mesmo por preocupar os líderes desses agrupamentos. Alegam que, numa comunidade, a coisa mais difícil é conseguir estabelecer o que chamam de "grupo base", pessoas que resolvam de fato se estabelecer, construindo suas casas e, se possível, constituindo famílias, requisitos fundamentais, segundo eles, para que se crie um vínculo a partir do qual a formação desse grupo venha garantir a existência comunitária, a despeito das vicissitudes que sempre ocorrem.

Não conseguindo formar esse "grupo base", isso faz com que a subsistência da comunidade dependa de recursos externos. Entre essa fontes estão as vivências realizadas na comunidade para visitantes, nas quais, entre outras coisas, se pratica a ioga, ensinam-se técnicas meditativas e trabalha-se a terra, cobrando para isso uma taxa. Outra fonte de recursos, a maior de todas, vem das famílias, da renda própria dos membros ou de doações.

Assim, as pessoas por lá passam, ou permanecem pelo tempo acima aludido. Invariavelmente, depois desse período, voltam ao local de origem e retomam as atividades da vida outrora negada, sem terem, contudo, operado um rompimento identitário com o mundo que abandonaram temporariamente. Tal situação se evidencia quando é constatada a dependência financeira dessas pessoas em relação às suas famílias que permaneceram nos grandes centros.

A questão do não rompimento com a sociedade mais ampla também pode ser percebida pela imersão completa da comunidade alternativa na ordem estabelecida, exemplificada, por exemplo, pela posse legal da terra, muitas vezes pela forma como se dá a utilização da mão-de-obra dos habitantes nativos das cidades onde se encontram e pela existência de um estatuto juridicamente reconhecido. Isso configura um paradoxo entre, de um lado, um ideal a ser atingido de evasão do sistema e, de outro, o vivenciamento dos mesmos mecanismos de interação social vigente na sociedade mais ampla. 
Nota-se, além disso, que também se beneficiam desse sistema na medida em que, em sua grande maioria, são originários das classes médias dos grandes centros urbanos do sul do país e mantêm, como retaguarda, famílias que os sustentam, através da remessa de mesadas e contribuições em diversos sentidos: seguro saúde, viagens, etc. Existe ainda um outro pequeno grupo de pessoas que possui renda própria, advinda de bens imóveis mantidos nos grandes centros. Na verdade observamos que, em certo sentido, é o próprio sistema social que acaba por sustentar a alternativa.

Talvez a interação existente, entre o sistema tão combatido e a "vida alternativa", possa ser compreendida um pouco além do aspecto da mera sustentabilidade dessas experiências - da Fráter, em particular. Se deslocarmos nosso foco de análise e nos imaginarmos agora observando a comunidade de cima e o fluxo constante de pessoas que passam por ela e retornam à sociedade mais ampla, podemos perceber claramente que algo se desenvolve em seu interior, devolvendo-os ao sistema, e que esses laços mantidos com a sociedade explicam, por si só, apenas em parte, a transitoriedade das pessoas no interior das experiências alternativas.

Quando perguntados sobre o porquê dessa dificuldade de enraizamento na comunidade, respondem sempre que a passagem na e pela comunidade é vista como um processo, no qual a experiência de viver na Fráter constitui uma etapa num caminho próprio a ser trilhado por cada pessoa, de forma individual. Viver na comunidade proporciona, para esses sujeitos, uma oportunidade de vivenciamento subjetivo de algo "novo", de uma "energia" nova que os torna conscientes de sua marcha e, invariavelmente, as reconduz ao contexto social de origem.

Dessa maneira, tais projetos acabam por agir como uma instância reintegradora dos indivíduos ao sistema tão combatido, transformados numa espécie de "apêndice" desse mesmo sistema. Ou seja, os projetos, através da experiência que proporcionam às pessoas, "preparam" os sujeitos abrindolhes uma porta para a reinserção. Na verdade, a palavra "reinserção" talvez não seja o termo mais adequado para o movimento verificado, na medida em que sendo a comunidade, da maneira como está sendo vista, parte integrante do sistema social, o que acontece é um movimento de pessoas no interior da própria sociedade ampla através das diversas instâncias que a compõem.

Com isso em mente, retornamos agora a Mannheim e aos conceitos de utopia e ideologia.

Quando foi realizada acima a discussão sobre o conceito de comunidade, foi ressaltado que o objeto deste trabalho se constrói a partir e em torno do mito da "comunidade utópica" e podemos perceber que este conceito de comunidade está sendo associado à primeira idéia utilizada por Mannheim, a concepção de utopia: "Chamaremos utópicas somente as orientações que transcendam a realidade e que, ao serem postas em prática, tendam a destruir, parcial ou completamente, a ordem de coisas existentes em determinada época" (Mannheim, 1956, p. 179). No entanto, o autor apon- 
ta para o fato de as "idéias transcendentes" terem sempre perpassado os períodos históricos, mas nem sempre constituindo utopias. É justamente para sublinhar essa característica e fazer essa diferenciação que realiza, nesse ponto, uma importante distinção entre dois termos fundamentais em sua obra e no entendimento do tema proposto, qual seja, o estabelecimento das dessemelhanças entre os conceitos acima citados.

A similitude principal entre eles reside no fato de que ambos trazem em sua constituição idéias que não se enquadram na ordem social existente - nas palavras de Mannheim "transcendentes à situação" - e se pautam por elaborações imaginárias de algo para além da realidade vivida. Entretanto, o segundo conceito, as ideologias, nunca logram, de fato, a realização do conteúdo projetado, e "(...) embora muitas vezes se tornem motivos bem intencionados da conduta individual, seus significados são geralmente desvirtuados quando postos em prática" (Mannheim, 1956, p. 181). O autor cita, como exemplo, a contradição existente na idéia cristã do amor fraterno numa sociedade como a nossa, onde o indivíduo se vê compelido à renúncia e onde a realidade do convívio social não se encontra organizada de acordo com esse princípio cristão.

A diferença fundamental e mais marcante entre as ideologias e as utopias, ainda segundo Mannheim, reside no fato de que as utopias conseguem, além de transcender a realidade vivida, transcender também a própria forma ideologia, na medida que logram, “(...) por meio de uma contra-atividade, transformar a realidade histórica existente em algo que esteja mais de acordo com suas próprias concepções" (Mannheim, 1956, p. 182). Ou seja, as utopias configuram a efetivação de um rompimento com a realidade vivida - mesmo que apenas em alguns aspectos - e uma projeção dos desejos humanos em direção a uma situação almejada. Nesses termos, a relação entre a utopia e a história real dos homens constitui uma relação dialética, na medida em que todas as épocas históricas forjam idéias e valores que apontam para um "ideal social", para um modo de vida alternativo. Assim, a realidade vivida gesta dentro de si sua própria oposição e cria, muitas vezes, a possibilidade de sua superação.

Mannheim nos mostra, também de forma perspicaz, o modo pelo qual o sistema social, muitas vezes, vive a ideologia metamorfoseada em utopia e aponta a maneira com que idéias que visam a transcendência de uma ordem negada podem atuar no sentido de legitimar essa mesma ordem estabelecida e, ao invés de apontarem para um futuro a ser construído, operam no sentido de subscreverem o status quo.

\section{O simbolismo e a alegoria do novo}

Possivelmente, a compreensão do modo como as ideologias se alegorizam, muitas vezes se apresentando aos homens sob a forma de utopias, possa ser conseguida a partir de uma pequena digressão sobre a matéria-prima das elaborações míticas e imaginárias, qual seja, o universo simbólico. 
O simbolismo, dentro da conceituação corrente, presume a capacidade do estabelecimento de um vínculo entre dois termos, de maneira que um represente o outro (cf. Castoriadis, 1991, p. 155). É essa capacidade que, segundo autores como Merleau-Ponty, nos distingue como seres culturais, capazes de criar relações com o ausente, com o tempo (passado, presente, futuro) e com os objetos da realidade vivida, utilizando a linguagem como principal instrumento para esse fim.

Dentre todas as orientações teóricas que trabalham com a questão das representações e do simbolismo, a corrente materialista, a nosso ver, apresenta uma contribuição singular ao entendimento dos processos sociais ao salientar o caráter alegórico dos sistemas simbólicos, através da apreensão da organização interna a cada grupamento social e das determinações que tal sistema sofre a partir de suas condições de existência econômica e política.

A obra de autores como Bourdieu é emblemática dessa tentativa de retificação de uma chamada "teoria do consenso" - herdeira de uma tradição kantiana e que tem como principais expoentes Cassirer, Sapir, Durkheim e Lévi-Strauss - e sua visão acerca dos sistemas simbólicos como responsáveis por um acordo tanto quanto ao significado dos símbolos quanto ao significado do mundo. A compreensão de tal visão pode ser conseguida a partir do entendimento de como se articula o pensamento da principal matriz da escola francesa, Émile Durkheim, no tocante à noção das "formas primitivas de classificação" (Durkheim \& Mauss, 1981).

A postura durkheimiana busca ver a organização social como constituindo a base do sistema de classificação das coisas, ou seja, o sistema lógico reproduzindo o sistema social e suas relações, de forma a se impor sobre os sujeitos e regulando o modo como os agentes dão sentido às suas práticas. Assim, a hierarquia lógica não seria senão um outro aspecto da hierarquia social, sendo que a "unidade de conhecimento não é outra coisa senão a própria unidade da coletividade, estendida ao universo" (Durkheim \& Mauss, 1981, p. 398). Ou seja, foi a partir da concepção de que as coisas formavam um todo junto ao corpo social que estas (as coisas) puderam encontrar seu lugar na natureza. A ordem dos objetos obedeceria a uma ordem social e a cultura passaria, então, a restringir-se a uma função de integração moral e lógica e que reproduz, a seu modo, a hierarquia que classifica e reparte os homens:

As relações lógicas constituem então, em certo sentido, relações domésticas. Às vezes até, como vimos, são totalmente comparáveis àquelas que existem entre o senhor e a coisa possuída, entre o chefe e seus subordinados. Poder-se-ia até perguntar se a noção, tão estranha do ponto de vista positivo, da precedência do gênero sobre a espécie não apresenta aqui sua forma rudimentar. Assim como, para o realista, a idéia geral domina o indivíduo, do mesmo modo que o totem do clã domina o dos subclãs e, mais ain- 
da, o totem pessoal dos indivíduos; e aí onde a fratria conservou sua consistência primitiva, ela tem sobre as divisões que compreende e os seres particulares que nela são compreendidos uma espécie de primazia (Durkheim \& Mauss, 1981, p. 452).

Nestes termos, a "teoria do consenso" acaba por diluir a problemática da dominação, na medida em que tal "sociocentrismo" (o termo é de Durkheim e Mauss) a "naturaliza" e a remete a uma relação de íntima correspondência a uma ordem lógica dos objetos naturais.

Evidentemente, Durkheim reconhece a problemática da crescente divisão interna dos grupos; porém, em sua ótica, tal situação seria recuperada a partir de um equilíbrio, subsistindo sempre "o esquema nuclear, segundo o qual a organização das idéias corre paralela à organização da sociedade" (Miceli, 1992, p. XVII).

O próprio Durkheim acaba por reconhecer a função social do simbolismo como um instrumento de construção da realidade, na medida que "funciona" como elemento de interação da sociedade "através do consensus acerca do sentido do mundo social que contribui fundamentalmente para a reprodução da ordem social: a integração lógica é a condição da integração moral" (Bourdieu, 1989, p. 10). No pensamento durkheimiano as "formas primitivas de classificação" constituem-se no plano conceitual e aparecem como uma etapa de superação, um estágio mais complexo sob o qual se deu o enfraquecimento progressivo de um estágio puramente afetivo.

As limitações de uma "teoria do consenso" vão desde o fato de constituir uma "teoria da integração lógica e social de representações coletivas" - inspirada no paradigma durkheimiano - ao fato de desprezar as funções econômicas e políticas dos sistemas simbólicos em detrimento de uma ênfase na análise interna das mensagens e bens de natureza simbólica. Neste quadro, a obra de autores como Bourdieu consiste numa tentativa de trazer à tona a forma como as condições materiais e institucionais presidem tanto a criação como a transformação dos chamados aparelhos de produção simbólica, cujo produto deixa de ser visto somente como mero instrumento de comunicação e conhecimento. Através da apreensão de como se organiza internamente esse campo, busca tornar claro o modo pelo qual o simbolismo se alegoriza, acabando por cumprir uma função ideológica e política, qual seja, a de legitimar a ordem em que se funda a dominação vigente ${ }^{7}$. Em suma, a partir do entendimento do caráter dinâmico da realidade histórica e socialmente determinada, na qual são produzidas idéias que buscam transcendê-la, é possí-

A esse respeito, consultar a excelente introdução feita por Sérgio Miceli à coletânea de textos de Pierre Bourdieu, intitulada A força do sentido (Miceli, 1992). vel que compreendamos os processos pelos quais a idéia de alternativa muitas vezes mascara a ideologia, de maneira que esta encontre espaço para agir e cumprir seu papel legitimador da ordem.

O pensamento desiderativo esbarra na história e pode vir a ter como produto, através da ação dos chamados "aparelhos de produção simbólica" - que estão sempre intimamente ligados ao sistema vigente - um 
tipo de ação que está muito mais próxima de uma "práxis repetitiva ou mimética", do que de uma práxis inovadora, que aponta para a consubstanciação da utopia (cf. Lefevre, 1968). A ideologia, por ignorar as contradições, estaria, nessa concepção, muito mais próxima de uma teoria do consenso do que da utopia, pois esta operaria no sentido de um confronto e de um rompimento com o quadro da realidade existente ou lançaria "cores complementares" a esse mesmo quadro.

O mito da "comunidade utópica", que permeia a maioria dos projetos em torno da construção de uma sociedade alternativa, comumente mostra-se, na prática, tão somente uma ambição de vivenciamento da ruptura, que pode esconder uma tentativa de mera reprodução dos mecanismos de interação presentes na sociedade vigente. Certamente, a ideologia utiliza-se dos sistemas simbólicos para exprimir-se e a chave para a compreensão sociológica de tais sistemas (bem como os mecanismos pelos quais sua eficácia se dá) reside no "desmonte" e na análise dos mesmos, através dos agentes que comungam nessas experiências.

É precisamente neste âmbito que se localiza o objeto de pesquisa ora analisado. O esquadrinhamento dos espaços e das concepções produzidas no interior da comunidade nos mostra como ambos se revestem de um simbolismo que permite subjetivamente que a alternativa seja vivificada por seus agentes. Objetivamente, percebemos que a maneira com que tais sujeitos se relacionam com a sociedade mais ampla e, mais especificamente, com o local de origem, se dá não na forma de um rompimento identitário com essa mas na forma de uma dependência que encontra sua face mais visível na esfera financeira, mas que se estende, muitas vezes, por múltiplos aspectos.

Vemos que o produto social que emerge dessa experiência - olhando-a não a partir do que produz nos indivíduos mas analisando-a em bloco, em contraposição ao que se coloca como alternativa, ou seja, ao sistema social vigente - acha-se localizado não no nível da utopia, do rompimento, da maneira como conceitua Mannheim, mas da repetição e, portanto, da ideologia. Nesses termos, a comunidade alternativa acaba não apenas por constituir uma instância integrada ao sistema tão combatido, mas também por cumprir uma função bastante específica, que é o ato de reconduzir as pessoas que por lá passam ao contexto social outrora negado.

É necessário destacar, nesse ponto, não apenas que a experiência cotidiana desenvolvida na comunidade, que através da questão espiritual acaba por reforçar a visão de processo, de caminhada individual em direção à auto-descoberta, ao auto-conhecimento, é responsável pela recondução desses sujeitos a seus antigos contextos sociais. É preciso que a comunidade também ofereça a possibilidade a seus agentes de refletirem sobre seu futuro no agrupamento e os ciclos naturais, como analisado, também desempenham um importante papel nesse processo. $\mathrm{O}$ fato de pensarem o tempo em termos de ciclos naturais, sendo que o ciclo que "permite" a vida comunitária termina em meados de outubro, acaba por impelir os sujeitos a esta- 
belecerem uma conexão espacial extra-comunidade, que se completa, invariavelmente, na sociedade de origem. Em outras palavras faz-se necessário, sob o risco de "ficar mofado", devido à presença das chuvas torrenciais que marcam o período das águas, buscar-se uma alternativa à alternativa, pois esta (a vida "comunitária") não se mostra como algo vivível em todos os meses do ano. A época da seca constitui, portanto, não apenas o momento de se viver comunitariamente, mas também o momento da reflexão, sendo que a alternativa à alternativa acaba constituindo, invariavelmente, a volta ao contexto social antes negado.

Tudo isso contribui para que a vida como um todo seja vista e vivida subjetivamente por esses sujeitos como um processo, no qual a Fráter acaba por constituir uma importante etapa dessa caminhada. Volta-se ao contexto social de origem, esperando-se por novos sinais que indiquem os próximos estágios a serem vividos e espera-se poder espalhar as coisas boas aprendidas na comunidade. Ou seja, vive-se na Fráter uma experiência subjetiva significativa para aqueles que a comungam, embora uma análise objetiva do projeto como um todo possa nos revelar a comunidade como instância integrada ao sistema e desempenhando uma função moralizante e extremamente eficaz do ponto de vista da integração social. Neste ponto, como se procurou demonstrar, o sistema simbólico desempenha um papel crucial, na medida em que transfigura a ideologia em utopia mascarando o conservantismo em "cultura alternativa".

\section{Mito e história: a possibilidade do novo}

Evidentemente, a história sempre desencadeia a possibilidade do "novo". O próprio fato de a sociedade moderna ter gestado a possibilidade de superação do caráter cíclico que marca o tempo nas "sociedades arcaicas" já o indica e apesar dos sistemas simbólicos atuarem, muitas vezes, no sentido do mascaramento da ideologia sob o rótulo do "novo", este sempre encontraatravés da ação inventiva das mentes humanas - uma forma de expressar-se e de apontar para uma nova ordem.

Nem sempre essa ação é consciente por parte dos seus agentes e, por vezes, o que é intersubjetivamente "novo" é vivido objetivamente como repetição. Neste sentido, cremos que o estudo de Martins acerca do imigrante, a partir do que conceituou como a "crise do Brasil agrário", é elucidativo desse processo desajustamento/ajustamento, embora numa conjuntura diversa da analisada. Nesse trabalho, a imigração é vista como um processo em que a ressocialização do imigrante na sociedade de adoção se efetua a partir, primeiramente, de uma etapa de desajustamento, diante de "uma inadequação entre o sujeito e o grupo", por fatores sociais que, na conjuntura analisada, reduziram o sujeito à condição de ser despojado de toda propriedade que não fosse o trabalho e, como conseqüência, das relações sociais que não derivavam dessa nova condição. Tal fase de "dessocialização" aparece marcada por um rompimento da identidade do 
sujeito e de uma perda, por parte desse, de um grande número de relações sociais e reduzindo-as a um grupo primário (cf. Martins, 1973, p. 20).

Para Martins, migrar corresponde a um processo de "desajustamento/ajustamento" onde a última fase corresponde, precisamente, a um restabelecimento de relações sociais no interior da sociedade de adoção, a partir dos novos papéis que nela o imigrante passa a desempenhar. O processo migratório, dessa forma, suprime a outrora inadequação entre o sujeito ou o grupo na sociedade de origem, e restaura os laços sociais através da recompensa subjetiva que proporciona, “(...) dentro de um evento historicamente determinado pela expansão do modo capitalista de produção" (Martins, 1973, p. 21-20). O autor nota, no entanto, que um processo social só é ressocializador quando opera no sentido de promover o que chama de "ruptura na identidade do sujeito", como forma de reajustá-lo a uma nova estrutura social e não quando referida, tão somente, a um ajustamento funcional a papéis sociais. Essa nova identidade constituída permite que o sujeito vivencie a ruptura, na medida em que funda um comportamento que nega legitimidade à sociedade de origem (cf. Martins, 1973, p. 23-24). Configura-se, aí, o que Lefevre conceitua como práxis inovadora.

Essa inovação se efetua - entre outras coisas - por um privilegiamento, no plano da consciência, de um modo de vida camponês não mediado, onde o que é inovador, objetivamente, é vivido subjetivamente como algo repetitivo, portanto, conservador. O projeto preconizado tem como elemento central uma apologia da comunidade camponesa pré-capitalista e o projeto imaginário do imigrante se norteia, neste sentido, também pela comunidade utópica. Dessa forma, Martins aponta para o duplo aspecto desse processo social: de um lado e, intersubjetivamente, constituindo um "(...) foco de resistência, passiva ou não, às rupturas estruturais da sociedade; objetivamente, porém, a utopia comunitária se insere dinamicamente nas relações sociais como resistência aos efeitos estruturais dessas rupturas; isto é, inverte seu sentido. Alienadamente, o camponês formula e desencadeia a sua oposição à sociedade capitalista" (Martins, 1973, p. 27-28). Assim, essa oposição, à medida que compõe uma negação da idéia constitutiva do sistema, que é a de sociedade - enquanto contrato, vínculo racional, fruto da razão abstrata que se traduz num querer objetivamente dado (cf. Tönnies, 1947, p. 72-89) - também constitui uma negação, portanto, do próprio capitalismo. A utopia comunitária ressocializa o imigrante, na medida de sua significação e implicação como resistência à expansão do capitalismo e como supressão subjetiva da mediação coisificadora da mercadoria nas relações entre os homens (cf. Martins, 1973, p. 29).

Evidentemente, a experiência desenvolvida por ambos os grupos (imigrantes/alternativos) foram constituídas a partir de situações particulares e, portanto, não generalizáveis. Dentro disso, a primeira ponderação necessária diz respeito à conjuntura vivida por cada um deles; no caso dos imigrantes, a experiência desenvolvida deriva da emergência do modo capitalista de produção que ora se instaurava e, no caso dos alternativos, o que temos é esse processo já 
consolidado. A segunda observação a ser feita, e como decorrência da primeira, reside no fato de os imigrantes, como exposto, terem tido como resultado da conjuntura que viviam sua fase de "dessocialização" marcada por uma perda de um grande número de relações sociais, que as reduziu a um grupo primário; ao contrário, o que vêem os alternativos é, justamente, uma diluição das relações vivenciadas nos grupos primários e a passagem à sociedade mais ampla, marcada por uma ampliação dos sistemas simbólicos.

O que temos em comum entre ambos é que: 1) norteados pelo mito da comunidade utópica, desencadeiam uma oposição à idéia de sociedade, idéia essa que é constitutiva do sistema, e o fazem como reação aos efeitos impressos em cada um pela maneira que o referido sistema subjuga as relações sociais, tendo como referência os grupos primários e a sociedade pensada num sentido mais amplo; 2) a idéia de comunidade aparece, nos dois casos, como a maneira possível de um imaginário ganhar substância de realidade em torno de um modo de vida alternativo; 3 ) em ambos os casos fica patente a mesma criação imaginária de um restabelecimento de relações diretas, não mediadas entre os homens, presente na utopia comunitária. A comunidade utópica renasce no imaginário dos alternativos como negação a uma realidade vivida, como esperança de refazer "laços perdidos", como possibilidade de buscar algo de si supostamente perdido e de preencher o "vazio interior", instilado pela sociedade moderna a partir da ampliação dos sistemas simbólicos que marca a passagem da infância à idade adulta; 4) da mesma maneira, também é muito visível, em princípio, como os alternativos vivenciam na sociedade de origem um processo de crise de sua identidade social que também funda neles um comportamento, à primeira vista, negador da legitimidade dessa sociedade, criando uma situação onde a ruptura - nos moldes que falava Martins - aparece como possibilidade. Assim como os imigrantes, tais sujeitos vivem o começo de um processo de "dessocialização", cujo entendimento só pode se efetivar a partir da compreensão das determinações históricas que cada sujeito vivencia dentro de seu grupo de origem.

O primeiro paradoxo, fruto da experiência que um e outro vivenciam, decorre daquilo que desenvolvem em termos objetivos e subjetivos. Enquanto os imigrantes, segundo a visão de Martins, experimentam objetivamente o "novo" vivido subjetivamente como repetição, os alternativos, ao contrário, vivem a objetividade da ideologia transfigurada subjetivamente como inovação. Isso certamente decorre do fato de que, devido à aludida situação particular dentro da qual tais experiências se forjaram, o alternativo não vivencia, de fato, uma ruptura com a sociedade de origem. Isso se explicita diante da constatação de que continua preso a uma situação de dependência econômica em relação à família ou, além disso, ter sua relação com a sociedade local marcada por uma inserção completa na ordem: posse legal da terra, influência política no município, contratação de mão-de-obra na cidade, etc. 
Existe, de fato, uma negação da sociedade de origem, como produto de um processo de ruptura na identidade social do sujeito. Só que essa ruptura não se completa devido a não se constituir uma estrutura social historicamente nova no outro pólo. Não existe, dessa maneira, uma práxis inovadora nas relações sociais - no nível do sistema - por não se consumar uma negação efetiva da legitimação da sociedade prévia. Há um vivenciamento subjetivo de um imaginário de ruptura, que os remete à comunidade utópica através da ritualização constante a que seus cotidianos estão submetidos.

A constituição da comunidade alternativa permite que essa idéia seja vivida por esses sujeitos, mesmo que uma análise mais atenta possa nos mostrar a existência dos mesmos mecanismos de interação social e conformidade ao sistema presentes em tais experiências. Essa ruptura, por não se completar objetivamente no nível do sistema social e permanecer apenas no campo da subjetividade, não permite uma ressocialização no interior desses grupos. Diante da impossibilidade disso se consubstanciar, a vivência alternativa "impõe", invariavelmente, "uma volta à sociedade de origem", onde a identidade pode ser refeita e onde se completa o ciclo "desajustamento/ajustamento". Em outros termos, a constituição do sujeito alternativo se dá enquanto fruto de uma elaboração simbólica que transfigura as mesmas relações existentes no capitalismo, metamorfoseando-as em "cultura alternativa", agindo como elemento que reinsere esses atores nos ambientes sociais de origem e que tolhe a possibilidade de ruptura com esse quadro. Enquanto o imigrante experimenta o "novo" de maneira objetiva, ainda que subjetivamente vivido como repetição, o alternativo, ao contrário, experimenta a vida comunitária vivenciada subjetivamente como "práxis inovadora".

A partir da discussão acima, é-nos possível perceber como, enquanto "mito da comunidade utópica", a idéia de transcendência e de volta às origens acaba por obscurecer a comunidade enquanto dimensão mesma da sociedade. Isto permite que, através da idéia da alternativa, a ideologia possa cumprir seu papel moralizante e ressocializador e a comunidade alternativa aparece como instância não apenas integrada, mas estritamente vinculada aos processos sociais da sociedade vigente.

\section{Considerações finais}

A partir da análise até aqui desenvolvida sobre a experiência da FraterUnidade, cremos que talvez seja interessante nos questionarmos - a partir da problemática do imaginário, do simbólico e da ideologia - sobre a possibilidade e o lugar das utopias no mundo moderno. Que o sistema vigente possui mecanismos sutis de controle social, que muitas vezes mascaram o conservantismo sob o rótulo da inovação, talvez seja algo do qual tenhamos poucas dúvidas. O que nos perguntamos, nesse momento, é a respeito do alcance desses mecanismos e sobre as brechas através das quais as utopias possam ser ou não forjadas nos interstícios da sociedade. 
Se, de um lado, pensarmos em termos de projeto, talvez o que tenhamos é a ideologia norteando a alternativa sob o rótulo do "novo". De outro lado, se pensarmos do ângulo dos seus integrantes, é provável que tenhamos aí uma inovação, a partir da experiência subjetiva que a experiência alternativa proporciona a essas pessoas, em termos da possibilidade de vivenciarem uma oposição aos efeitos produzidos, nos sujeitos, pela complexidade crescente da sociedade moderna.

Na Fráter, o sentimento de perda é minimizado. Vive-se subjetivamente um reencontro consigo mesmo e, ao voltar aos locais de origem, esses sujeitos sentem-se renovados e dispostos a enfrentar, com uma nova postura, as vicissitudes da vida. Se o grupo não vive a utopia frente ao mundo, os sujeitos a vivenciam enquanto busca da idéia de indivíduo e a vida em comunidade proporciona que esse ideal seja experimentado em sua vida cotidiana.

Dessa forma, talvez possamos falar não num rompimento definitivo, com um grupo instaurando uma nova ordem descolada do sistema social vigente, mas em rupturas que são vividas pelos sujeitos em momentos determinados, preenchendo essas brechas que vão sendo encontradas pelos homens na sociedade mais ampla. A imagem que melhor espelha essa idéia é a de uma linha, em cima da qual os sujeitos caminham construindo as suas vidas. Só que essa não é uma linha reta, é algo que oscila em determinados momentos e em ritmos inconstantes, marcando os instantes de uma maior aproximação ou distanciamento consigo mesmos. É precisamente dessa maneira que encaramos a experiência desenvolvida na Fráter: uma possibilidade de viver mais intensamente essa oscilação, no sentido de um vivenciamento subjetivo da utopia e em direção a uma busca de si mesmo. Talvez aí estejam elementos para pensarmos também a concretização objetiva desses projetos frente ao sistema social como um todo.

Cabe considerar, no entanto, que a principal defesa, no plano simbólico, da ideologia que defende a legitimação da ordem é a de que pensar contra ela constitui um projeto irrealizável (Brandão, 1982). Talvez seja por isso que muitas vezes esses projetos, até com relativa facilidade, são absorvidos pela trama de relações que "pensa" a eternidade desse mundo estabelecido e acabam sob o rótulo de reformistas, por vezes atuando no sentido de subscrever a ordem da qual se nutrem, através de sua contestação.

De qualquer forma, imaginar mundos e sociedades ideais - em tempos ou espaços diferentes - parece ser constitutivo do modo humano de viver em sociedade e isso só é possível porque também é essencialmente humano criar redes simbólicas que permitam que esses mundos sejam pensados. É evidente, também, que a emergência do novo está intimamente associada a esta capacidade.

Certamente, assim como esses mecanismos sutis muitas vezes podem nos envolver nessa alquimia da legitimação da ordem, talvez seja justamente a partir daí que a possibilidade da utopia, recriada como projeto, possa, enfim, começar a se concretizar. 
NOGUEIRA, Aico Sipriano. New Age communities in the Central Plateau- utopia, ideology and reafirmation of order. Tempo Social; Rev. Sociol. USP, S. Paulo, 13(1): 159-184, May 2001.

ABSTRACT: This article analyses the constitution of an alternative community in the central plateau of Brazil, based on what has been called 'new contemporary forms of sociability'. Using a theoretical-conceptual discussion on community, utopian community, myth, ideology, utopia and imaginary, the text suggests the possibility of taking the idea of alternative to the present social system as an expression, along with conservative thought and the possibility of the construction of the new.

\section{REFERÊNCIAS BIBLIOGRÁFICAS}

Abrams, Philip \& Macculloch, Andrew. (1976) Communes, sociology and society. Cambridge, Cambridge University Press.

Abreu, Jânio Caetano de. (1989) Comunidades do movimento alternativo: uma perspectiva autogestionária. Belo Horizonte, 247 p. Dissertação (Mestrado). Departamento de Ciências Administrativas da Universidade Federal de Minas Gerais.

ArrudA, Maria Arminda do Nascimento. (1990) Mitologia da mineiridade. São Paulo, Brasiliense.

Bourdieu, Pierre. (1989) O poder simbólico. Bertrand, Rio de Janeiro. . (1992) A economia das trocas simbólicas. São Paulo, Perspectiva.

BRANDÃO, Carlos Rodrigues. (1982) Lutar com palavras: escritos sobre o trabalho do educador. Rio de Janeiro, Graal.

Buber, Martim. (s/d) O socialismo utópico. São Paulo, Perspectiva. (1985) Sobre comunidade. São Paulo, Paz e Terra.

CAstoriadis, Cornelius. (1991) A instituição imaginária da sociedade. São Paulo, Paz e Terra.

Coelho, Paulo. (1990) O diário de um mago. Rio de Janeiro, Rocco.

DurkheIM, Émile \& Mauss, Marcel. (1981) Algumas formas primitivas de classificação. In: MAuss, Marcel (org.). Ensaios de sociologia. São Paulo, Perspectiva.

Eliade, Mircea. (1992) O mito do eterno retorno. São Paulo, Mercúrio.

Galeano, Eduardo. (1995) Walking words. New York, Norton.

Heller, Agnes. (1982) O homem do renascimento. Lisboa, Presença.

Lefevre, Henri. (1968) A sociologia de Marx. Rio de Janeiro, Forense Universitária.

utopia, community, imaginary, ideology, myth, counter-culture. 
MannheIm, Karl. (1956) Ideologia e utopia: introdução à sociologia do conhecimento. Rio de Janeiro, Globo.

MARSHALl, Gordon (org.). (1994) The concise Oxford dictionary of sociology. Oxford, Oxford University Press.

Martins, José de Souza. (1973) A imigração e a crise do sistema agrário. São Paulo, Pioneira.

MARX, Karl. (s/d) Prefácio à contribuição à crítica da economia política. In: Obras escolhidas. vol. 1, São Paulo, Alfa Ômega.

\& ENGELs, Friedrich. (1987) A ideologia alemã. São Paulo, Hucitec.

Miceli, Sérgio. (1992) A força do sentido. In: Bourdieu, P. (org.). A economia das trocas simbólicas. São Paulo, Perspectiva.

Nisbet, Robert. (1969) La formacion del pensamiento sociológico. vol. 1. Buenos Aires, Amorrortu Editores.

NogueIRA, Aico Sipriano. (1986) FraterUnidade - estudo de uma experiência de comunidade alternativa no Planalto Central do Brasil. São Paulo, 256 p. Dissertação (Mestrado). Departamento de Sociologia da Facudade de Filosofia, Letras e Ciências Humanas da Universidade de São Paulo.

TönNIES, Ferdinand. (1947) Comunidad y sociedad. Buenos Aires, Lusanda.

Unger, Nancy Mangabeira. (1991) O encantamento do humano-ecologia e espiritualidade. São Paulo, Edições Loyola.

ZABLOCKI, Benjamin. (1980) The joyful community. Chicago, The University of Chicago Press. 